\title{
H-M2MMAC: Uma Nova Abordagem Híbrida de Protocolo MAC Multicanal para Comunicação Muitos-para-Muitos
}

\author{
Daniel Alexandro R. Adauto ${ }^{1}$, Renato M. de Moraes ${ }^{1}$ \\ ${ }^{1}$ Centro de Informática - Universidade Federal de Pernambuco (UFPE) \\ 50740-560 - Recife - PE - Brazil \\ \{dara, renatomdm\}@cin.ufpe.br
}

\begin{abstract}
This paper describes a Hybrid and Adaptive Many-to-Many Communication Multichannel MAC Protocol for 802.11-based Wireless Networks with the Split Phase architecture. This approach, called H-M2MMAC, enables the transmission of data during the ATIM Window in channels that are unique for exchanging data packets under high-load conditions on the network. In order to evaluate the performance of the protocol, it is presented a mathematical model that has as metric the aggregate saturation throughput of the network. This model is evaluated numerically and its results are compared with other related multichannel protocols. Results show that H-M2MMAC outperforms the other protocols.
\end{abstract}

Resumo. Este artigo apresenta uma Abordagem Híbrida e Adaptativa de Protocolo MAC Multicanal para Comunicação Muitos-para-Muitos baseada na arquitetura Split Phase. Esta abordagem, denominada H-M2MMAC, viabiliza a transmissão de dados durante o intervalo da janela de negociação nos canais que são exclusivos para troca de pacotes de dados sob circunstâncias de alta carga na rede. Para se avaliar o desempenho do protocolo, é apresentado um modelo matemático que tem como métrica a vazão agregada de saturação da rede. Tal modelo é avaliado numericamente e seus resultados são comparados com os de outros protocolos multicanais relacionados. O H-M2MMAC apresenta desempenho superior aos demais protocolos.

\section{Introdução}

As Redes $A d H o c$ são formadas por um conjunto de nós com interfaces sem fio que se organizam de forma dinâmica dentro de uma topologia temporária e arbitrária, sem a necessidade de um ponto de acesso central [Rubinstein et al. 2006]. Elas podem se mostrar incrivelmente úteis às autoridades competentes no que diz respeito a situações de desastres naturais e antropogênicos, e têm ampla aplicação em Internet das Coisas. Porém, seus nós sofrem limitações em termos de memória, vida útil das baterias e poder de processamento. Concomitantemente, os nós devem ser capazes de lidar com outras funcionalidades da rede como o controle de acesso ao meio, roteamento e sinalização. No padrão IEEE 802.11 são especificados pelo menos três canais não sobrepostos [IEEE Computer Society LAN MAN Standards Committee 1997]. Entretanto, esses canais são subutilizados por muitos protocolos atuais da camada de enlace. Proporcionar à uma rede $a d$ hoc a possibilidade de transmitir em mais de um canal fornece vantagens como a redução de colisões de pacotes e aumento da vazão. Sendo assim, faz-se necessário implementar protocolos MAC (do inglês Medium Access Control) de múltiplos canais 
que sejam energeticamente eficientes, e que aproveitem de maneira inteligente os recursos disponíveis nos canais de comunicação.

Os protocolos MAC com múltiplos canais são classificados em quatro categorias principais: Dedicated Control Channel, Common Hopping, Multiple (ou Parallel) Rendevouz e Split Phase [Mo et al. 2008]. Os protocolos classificados como Dedicated Control Channel são baseados na existência de um canal exclusivo para controle e negociação de canais de dados. Sendo assim, é necessário que as estações estejam equipadas com pelo menos dois transceptores, tornando esta solução mais cara e ineficiente quando existem poucos canais. Os protocolos classificados como Common Hopping e Multiple Rendezvous são baseados em saltos de frequência, porém demandam mecanismos precisos de sincronização de tempo. Os protocolos classificados como Split Phase funcionam de maneira análoga ao Padrão IEEE 802.11 PSM (do inglês Power Saving Mode) [IEEE Computer Society LAN MAN Standards Committee 1997], onde todos os eventos da rede são executados dentro de intervalos entre beacons que são divididos em duas fases. A primeira etapa viabiliza, em um canal padrão predefinido, a troca de pacotes de controle entre as estações que desejam transmitir dados. À esta etapa dá-se o nome de fase de negociação ou Janela ATIM. O período da Janela ATIM é regido pelas regras do Padrão IEEE 802.11 DCF [IEEE Computer Society LAN MAN Standards Committee 1997], cujo funcionamento é baseado em prevenção de colisões através do CSMA/CA. A segunda etapa proporciona a troca efetiva de pacotes de dados (DATA Frame) nos canais previamente definidos durante a Janela ATIM. À esta etapa dá-se o nome de fase de comunicação ou Janela de Dados. As estações que não tenham pacotes a transmitir ou a receber passam a entrar no estado de suspensão denominado DOZE mode até o início do próximo intervalo entre beacons. Para informar à rede que os pacotes ATIM e de dados foram recebidos com sucesso, as estações receptoras devem enviar pacotes de reconhecimento (ACK).

Neste artigo é proposto um novo protocolo Split Phase MAC multicanal para comunicação muitos-para-muitos que possibilite a uma parcela dos nós da rede realizar transmissão de dados durante a fase de negociação, enquanto a outra parcela dos nós realiza Two-Way Handshake no canal de controle durante o intervalo da Janela ATIM (do inglês Announcement Traffic Indication MAP). A este modo de transmissão dá-se o nome de transmissão estendida e só deverá ser realizada em condições de alto tráfego da rede, o que irá caracterizá-lo como protocolo híbrido. Desta maneira, o protocolo será capaz de utilizar os recursos multicanais de maneira mais eficiente.

O resto do artigo está organizado da seguinte forma. A Seção 2 apresenta uma breve revisão da literatura relacionada ao trabalho aqui desenvolvido. A Seção 3 apresenta o novo protocolo híbrido de comunicação muitos-para-muitos com tecnologias atuais de rede sem fio, o H-M2MMAC. A Seção 4 apresenta o modelo analítico do protocolo proposto utilizado para a avaliação da vazão agregada de saturação. A Seção 5 apresenta a avaliação de desempenho, os resultados e a discussão em comparação com outros protocolos atuais relacionados. Por fim, a Seção 6 apresenta as considerações finais e indica trabalhos futuros.

\section{Trabalhos Relacionados}

O protocolo híbrido apresentado neste trabalho baseia-se na abordagem Split Phase e no Padrão IEEE 802.11 PSM. A Figura 1 ilustra o funcionamento de quatro protocolos Split 
Phase MAC multicanais durante dois intervalos entre beacons. Tais protocolos estabelecem soluções para a redução do consumo de energia em estações de rede sem fio. Em cada exemplo, são disponibilizados um canal padrão/controle (Canal 1), um canal de dados (dois canais para o exemplo do protocolo M2MMAC) e cinco estações (A, B, C, D e E) com cores especificadas na legenda da parte superior da Figura. Cada um dos canais é rotulado por uma cor diferente. A cor preta indica a ocupação do canal com contenção (duas ou mais estações disputam para transmitir dados). A cor ciano indica que o canal está ocupado por duas estações, sendo uma delas a única transmissora, indicando uma comunicação sem contenção. Se o canal for rotulado por uma cor correspondente à uma das estações, isso indica que tal estação está utilizando o canal para transmissão e recepção simultânea de pacotes de dados naquele intervalo de tempo específico. Já a cor cinza desvela os períodos onde os canais estão ociosos. Cada linha pontilhada colorida sobreposta aos canais representa a disponibilidade dos transceptores de cada estação para transmissão e recepção concorrente dos sinais.

O protocolo MMAC (do inglês Multi-channel MAC), proposto em [So and Vaidya 2004], destacou-se por ser um dos primeiros protocolos multicanais para redes ad hoc a solucionar o problema do terminal escondido multicanal. Este problema acontece pelo fato das estações não poderem monitorar mais de um canal simultaneamente, dado que cada estação possui somente um transceptor half-duplex. Consequentemente, as estações não conseguem evitar a ocorrência de colisões na rede pelo método tradicional do CSMA/CA. Adicionalmente, mecanismos de Detecção Virtual da Portadora são utilizados durante as duas fases dos intervalos entre beacons. A Figura 1(a) exemplifica o seu funcionamento. Na primeira fase, as estações que desejam se comunicar iniciam uma negociação de três vias (Three-Way Handshake) e indica nos pacotes de confirmação qual o canal a ser ocupado. Na fase de comunicação, ainda são trocados pacotes RTS e CTS. Isso faz-se necessário tendo em vista que os canais não são exclusivos a um par de nós, além de fornecer um maior nível de compatibilidade com os equipamentos legados que não participam do mesmo protocolo, mas que utilizam os mesmos canais. Uma das desvantagens deste protocolo é o desperdício dos recursos disponíveis nos canais exclusivos para troca de dados durante a fase de negociação.

O protocolo TMMAC (do inglês TDMA-based Multi-channel MAC), proposto em [Zhang et al. 2007], incorpora as vantagens proporcionadas pelo protocolo MMAC combinadas à abordagem de multiplexação por divisão de tempo (TDMA). A Janela de Comunicação é dividida em slots de tempo fixos, o que propicia às estações não envolvidas na comunicação de um determinado slot a possibilidade de entrarem em DOZE mode, alcançando desta forma uma maior eficiência energética. Como os recursos negociados durante a Janela ATIM são a combinação do canal e do slot de tempo (indicados nos pacotes de confirmação), o número de negociações pode ser ainda maior. Sendo assim, os autores ainda propõem um mecanismo de ajuste dinâmico da duração da Janela ATIM com base nos padrões de tráfego da rede. Porém, existe um trade-off a ser considerado. Quanto maior a janela de negociação, maior o desperdício dos recursos disponíveis nos demais canais exclusivos para troca de dados. A Figura 1(b) exemplifica o funcionamento do TMMAC. Na fase de comunicação, são trocados os pacotes de dados em slots específicos sem a necessidade da utilização de mecanismos de detecção virtual da portadora como pacotes RTS e CTS. Isto se torna possível pois cada slot de tempo é exclusivo para a troca de dados entre um par de nós. Entretanto, os autores afirmam que o TMMAC não é 

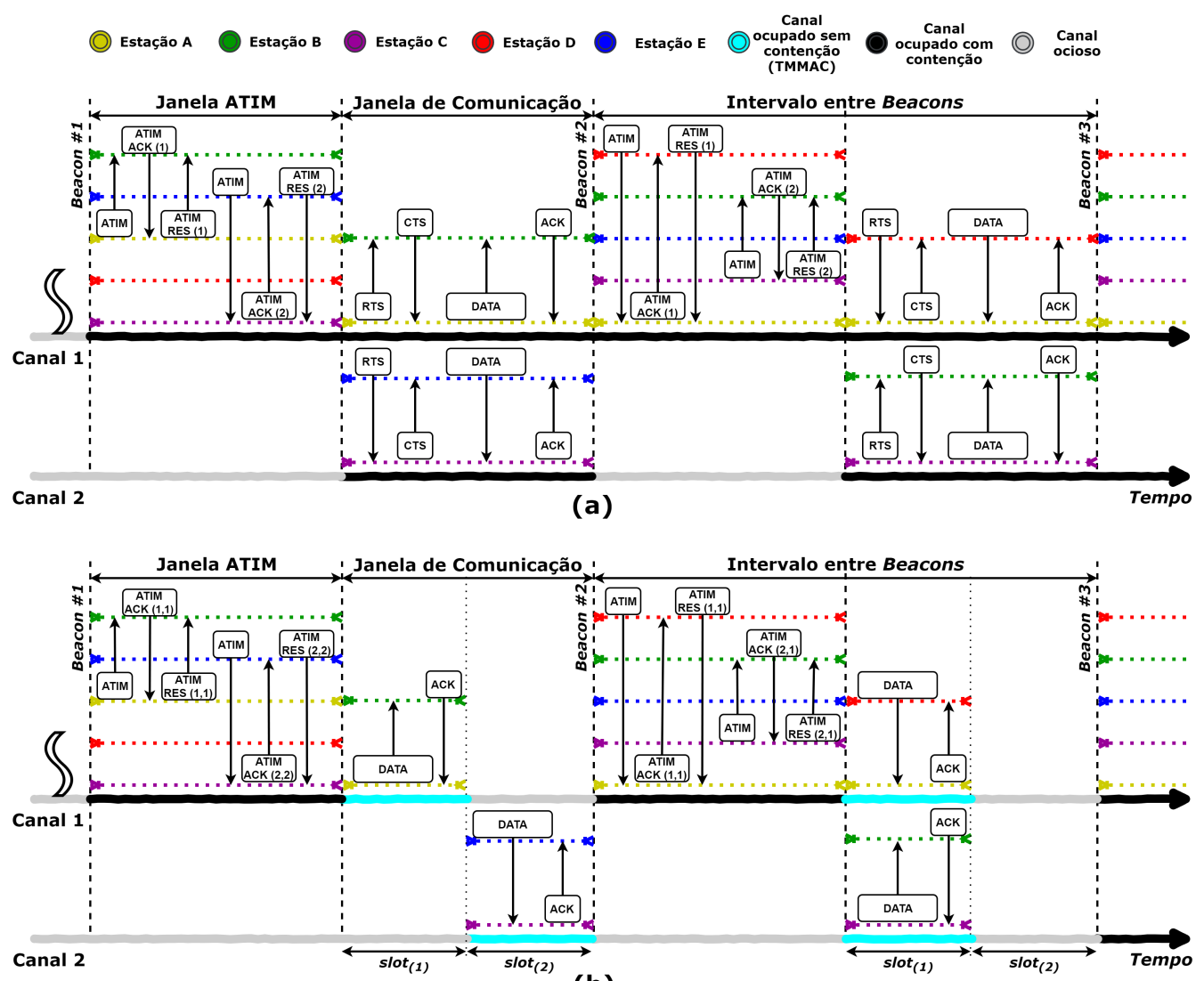

(b)
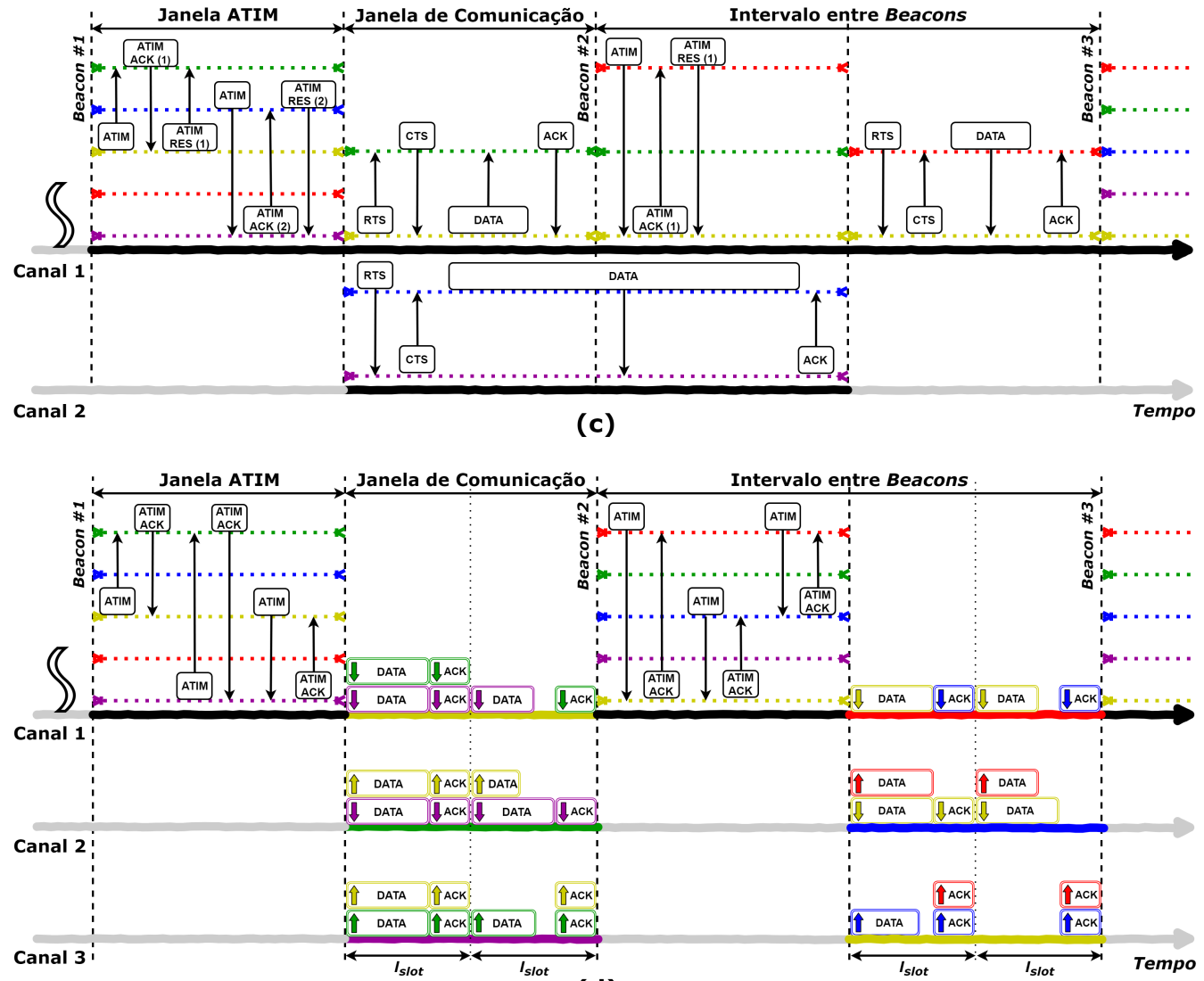

(d)

Figura 1. Diagramas temporais dos protocolos MAC multicanais correlatos. (a) MMAC, (b) TMMAC, (c) H-MMAC e (d) M2MMAC. 
um protocolo livre de colisões, pois não se pode garantir que todas as negociações foram realizadas com sucesso durante a fase de negociação.

O protocolo H-MMAC (do inglês Hybrid Multi-channel MAC), proposto em [Dang et al. 2015], tem por objetivo possibilitar a transmissão de dados durante a fase de negociação, enquanto uma outra parcela dos nós da rede realiza Three-Way Handshake no canal de controle durante o intervalo da Janela ATIM. Com isso, o desperdício dos recursos disponíveis nos canais exclusivos para troca de dados durante a fase de negociação é menor. A este tipo de transmissão dá-se o nome de transmissão estendida. Entretanto, os nós que utilizam este tipo de transmissão devem se abster de comunicar durante a janela de comunicação seguinte se caso o canal estiver ocupado, tendo em vista que estes nós não participaram das negociações ocorridas durante a janela ATIM e desconhecem quais canais estão sendo utilizados durante a fase de comunicação. Posto isto, nem sempre é vantajoso permanecer neste estado. A Figura 1(c) exemplifica o funcionamento do H-MMAC. Os autores afirmam haver vantagens no modo de transmissão estendido, principalmente em situações de alta carga de dados. O mesmo não se pode afirmar em casos onde há uma baixa carga. Por este motivo o protocolo é híbrido, ou seja, o modo de transmissão é selecionado conforme o nível de carga na rede. É importante ressaltar que a Figura 1(c) é um exemplo ilustrativo do H-MMAC. Como a carga da rede na Figura é baixa, o seu funcionamento real não admitiria a transmissão estendida neste caso.

Através da comunicação muitos-para-muitos (M2M, do inglês Many-to-Many) [de Moraes 2005, de Moraes et al. 2009], é exequível o aumento da capacidade de transmissão de dados e a diminuição do atraso fim a fim entre as estações da rede. Por meio de técnicas como MIMO (do inglês Multiple Inputs Multiple Outputs) e FDMA (do inglês Frequency Division Multiple Access), é possível proporcionar a comunicação entre diversos nós compartilhando o mesmo canal de comunicação de forma simultânea.

No contexto de comunicação muitos-para-muitos e da utilização de múltiplos canais, foi proposto em [Ghobad 2017] o protocolo M2MMAC (do inglês Many-to-Many Multichannel $M A C$ ). O protocolo exige que todos os nós da rede possuam um transmissor e um receptor, ambos simplex, compondo um transceptor integrado com cadeias paralelas de processamento de sinais que transmite sincronicamente em frequências diferentes, enquanto recebe dados em um único canal de frequência distinto. Os nós são equipados com um conjunto de $B$ antenas de recepção e uma única antena para transmissão. A rede deve dispor de $M$ canais de frequência não sobrepostos ortogonais. Adicionalmente, cada nó deve alcançar e ser alcançado por todos os outros nós da rede, sendo a comunicação sempre em único salto (do inglês single-hop). Durante a janela ATIM, no canal de controle estabelecido previamente, os pares de nós que conquistaram uma negociação com sucesso definem frequências diferentes de recepção, onde cada transmissor e receptor terá um canal de recepção exclusivo durante a janela de comunicação. Para cada nó é outorgado $(B-1)$ fluxos de transmissão que poderão ser utilizados como meio de recepção dos dados enviados por seus vizinhos. Essa limitação é decorrente da detecção de múltiplos usuários MIMO. Os fluxos de transmissão são negociados aos pares na janela ATIM e garantem a comunicação bidirecional entre um par de nós específico na janela de comunicação. O pacote ATIM irá indicar a quantidade de pacotes de dados a serem enviados e a frequência de recepção do transmissor na janela de comunicação. O nó destino deverá enviar um pacote ATIM-ACK indicando a sua frequência de recepção e o número 
de pacotes de dados que eventualmente ele tenha que transmitir ao nó fonte. Uma vez que a negociação tenha sido realizada com êxito, os pacotes de dados, juntamente com os pacotes de confirmação, poderão ser transmitidos de forma simultânea e bidirecional entre o par de nós enquanto houver espaço na janela de comunicação. Se algum nó não dispor de dados a serem transmitidos ou recebidos, ele deverá entrar em DOZE mode até o início do próximo intervalo entre beacons para economizar energia.

A Figura 1(d) exemplifica o funcionamento do M2MMAC. Na primeira janela ATIM, são realizadas três negociações de forma bem sucedida entre as estações A, B e C, perfazendo um total de seis fluxos de transmissão. Imediatamente após o início da janela de comunicação, a troca de pacotes de dados e dos seus respectivos pacotes de confirmação ACK é efetivada. É interessante notar que cada pacote de dados e de confirmação é rotulado com as cores referentes aos destinatários de cada transmissor. Uma nova rodada de transmissões é efetuada após o recebimento das confirmações. Para que haja um sincronismo na rede, cada rodada de transmissões só deve começar após transcorridos $l_{\text {slot }}$ segundos, onde $l_{\text {slot }}$ representa o tempo total para a transmissão do maior pacote de dados permitido pela rede, juntamente com a confirmação de recebimento. Por não ser caracterizado como um protocolo híbrido, o M2MMAC perde os recursos disponíveis nos canais exclusivos para troca de dados durante a Janela ATIM, assim como ocorre com os protocolos MMAC e TMMAC.

\section{O Protocolo Proposto H-M2MMAC}

Para melhor aproveitar as vantagens da comunicação muitos-para-muitos do protocolo M2MMAC, faz-se necessário evitar o desperdício dos recursos disponíveis nos $M-1$ canais exclusivos para troca de dados, combinando as vantagens do M2MMAC e do $\mathrm{H}-$ MMAC em um único protocolo. Sendo assim, é proposto um novo protocolo híbrido denominado H-M2MMAC. Além de recorrer aos recursos multicanais disponíveis e viabilizar a transmissão e recepção simultânea de múltiplos pacotes de dados utilizando a tecnologia baseada no Padrão IEEE 802.11, o H-M2MMAC delega aos nós a oportunidade de transmitir pacotes de dados durante a fase de negociação enquanto a outra parcela dos nós da rede realiza Two-Way Handshaking no canal de controle durante o intervalo da Janela ATIM baseando-se na condição de alto tráfego na rede. Neste caso, será possível reduzir o número de colisões de pacotes de controle na Janela ATIM do canal padrão, tendo em vista que a disputa ocorrerá apenas entre as estações que não estabeleceram fluxos de transmissão do tipo estendido na janela ATIM antecedente. Além disso, o H-M2MMAC poderá proporcionar uma melhoria substancial da vazão agregada de saturação. A colisão de pacotes é um dos fatores mais críticos no que diz respeito ao desperdício de energia das baterias das estações. Pacotes colididos são descartados, e a retransmissão requer mais energia. No geral, a comunidade científica busca apresentar protocolos MAC que melhorem a eficiência da comunicação entre as estações. Protocolos que elevem a vazão (throughput) da rede, diminuam a quantidade de colisões, e que sejam energeticamente eficientes. O H-M2MMAC se sobressai nestas três métricas.

\subsection{Modelos de Transmissão}

São definidos, de maneira equivalente ao protocolo H-MMAC, dois modos de transmissão para as estações. No modo normal (N-Tx), os dados devem ser transmitidos somente na 
janela de comunicação. No modo estendido (E-Tx), a transmissão pode se estender até a Janela ATIM do próximo intervalo entre beacons.

Cada par de fluxos de transmissão deve ser classificado como normal ou estendido. Se um nó contiver pelo menos um fluxo de transmissão estendido, ele deverá ser classificado como do tipo estendido, mesmo que um ou mais fluxos normais sejam utilizados pelo mesmo nó. Dois aspectos decisivos que estimarão a carga de tráfego na rede do H-M2MMAC são o número de nós que estão competindo no canal de controle, e o número de pacotes de dados que serão transmitidos pela estação fonte. Dito isto, a estação fonte poderá escolher o tipo do par de fluxos de transmissão mediante os seguintes critérios:

- As estações devem averiguar a densidade da rede mediante o número de colisões de seus pacotes de controle. Quanto maior o número de estações competindo na janela de negociação, maior o número de colisões. Quando uma colisão ocorre, o número de tentativas de retransmissão é incrementado. Se o número de tentativas de retransmissão ultrapassar um determinado limiar, a estação fonte decidirá se selecionará o tipo estendido mediante o número de pacotes de dados em seu buffer.

- Se caso a estação portar em seu buffer uma quantidade de pacotes de dados superior ao número de intervalos $l_{\text {slot }}$ presentes no período de comunicação, ela decidirá que o par de fluxos de transmissão será do tipo estendido e enviará um pacote ATIM para o receptor indicando esta escolha. O comprimento do intervalo de negociação, assim como o de comunicação, deve ser múltiplo de $l_{\text {slot }}$.

\subsection{Estruturas de Dados NAV e NIL}

São estabelecidas duas estruturas de dados para o funcionamento do protocolo proposto: NAV (do inglês Network Allocation Vector) e NIL (do inglês Neighbor Information List). O Padrão IEEE 802.11 especifica o NAV para manter os nós informados quanto ao conhecimento das informações do estado de cada canal. Sendo assim, se caso a estação verificar em seu NAV que um determinado canal de frequência está ocupado, ela se abstém de transmitir para evitar colisões. Adicionalmente, a estrutura NAV deverá classificar cada canal de frequência disponível como utilizável ou não utilizável durante a próxima fase de comunicação e informar a quantidade de pares de fluxos de comunicação em que o nó estará participando. As estações deverão registrar em seu NAV o canal de recepção que cada uma delas estará sintonizada na fase de comunicação. Para cada par de fluxos, o NAV ainda deverá informar a frequência para envio de pacotes de reconhecimento e a quantidade de pacotes a serem recebidos. Por fim, o NAV deverá registrar o endereço atual de sua estação.

A segunda estrutura de dados, denominada lista de informação dos vizinhos ou NIL, é armazenada na estação para registrar as principais informações de cada vizinho da rede, tais como: o endereço da estação, o canal de frequência ocupado pelo nó vizinho, a classificação das estações como Normal, Ongoing, Limited ou Unknown conforme descrito em [Dang et al. 2015], e o modo de transmissão definido como normal (N-Tx) ou estendido (E-Tx). Durante o intervalo de negociação, sempre que um pacote ATIM de uma estação vizinha é detectado, os campos canal e modo de transmissão da NIL poderão ser atualizados para o respectivo registro da NIL cujo campo endereço seja equivalente ao endereço de transmissão do pacote ATIM. A atualização da NIL deverá ser realizada por camadas superiores da rede. 


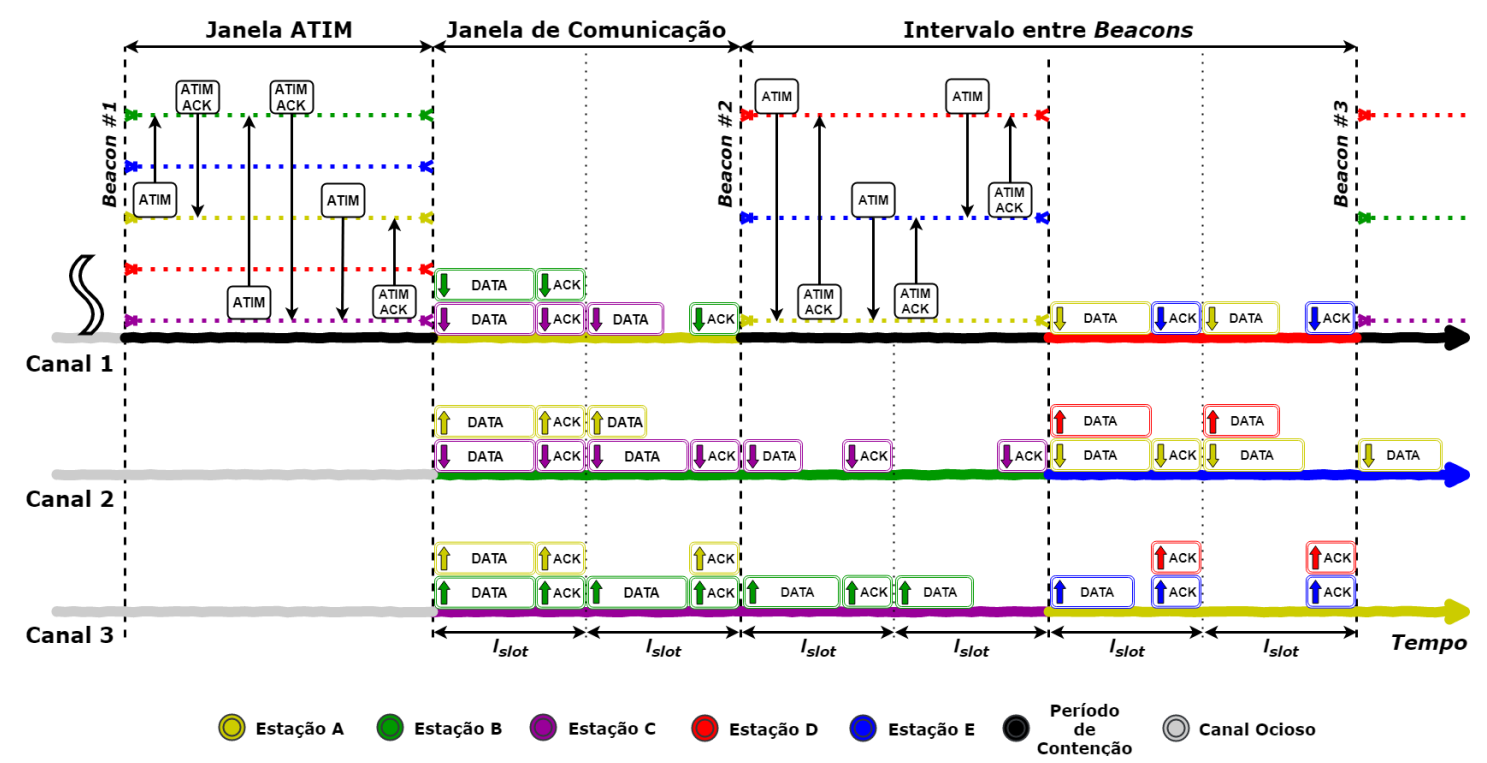

Figura 2. Diagrama temporal da negociação de fluxos e posterior transmissão de dados do Protocolo H-M2MMAC.

\subsection{Modo de Operação do Protocolo H-M2MMAC}

Inicialmente, para que seja estabelecido um enlace de comunicação entre um par de nós, a estação fonte deverá confirmar se é possível acomodar mais um fluxo de transmissão e verificar a classificação do destinatário na estrutura NIL. A estação destinatária deve obrigatoriamente ser classificada como tipo Normal ou Limited [Dang et al. 2015]. Caso contrário, o transmissor deverá esperar até o próximo intervalo entre beacons para tentar estabelecer um enlace de comunicação. Outro fator importante é a reserva de um canal de frequência disponível para recepção de dados. A estação fonte deverá consultar sua estrutura NAV e verificar o registro de utilização de cada canal. Se existirem um ou mais canais disponíveis, a seleção é realizada aleatoriamente. Caso contrário, deve-se aguardar pelo próximo intervalo entre beacons.

Sendo satisfeitas as premissas iniciais descritas anteriormente, a estação fonte decidirá qual o tipo do par de fluxos de comunicação a ser estabelecido com base no tráfego da rede, e transmite um pacote ATIM ao destinatário. A estação destinatária deverá consultar na sua estrutura NAV os campos de registro de utilização de cada canal e da quantidade de pares de fluxos de comunicação para verificar se ainda é possível acomodar mais um fluxo de recepção na próxima fase. Caso positivo, a estação decidirá definitivamente qual será o tipo dos fluxos de transmissão e de recepção e enviará um pacote de reconhecimento (ATIM-ACK) ao remetente. Caso contrário, um ATIM-NACK poderá ser enviado. Assim como proposto em [Ghobad 2017], um temporizador na estação transmissora poderá ser utilizado como forma alternativa, dispensando desta forma o envio do pacote ATIM-NACK. Uma vez que a negociação tenha sido realizada com sucesso, as estações devem migrar para os canais de recepção estabelecidos durante a fase de negociação e trocar os pacotes de dados durante a fase de comunicação.

A Figura 2 exemplifica o funcionamento do H-M2MMAC. Na primeira janela de comunicação, a estação A não possui fluxos de transmissão do tipo estendido, o que a 
identifica como uma estação do tipo de transmissão normal. Entretanto, as estações B e C possuem um fluxo do tipo normal (utilizado para transmissão dos dados à estação A) e um fluxo do tipo estendido (utilizado para a comunicação mútua entre B e C) cada uma. Sendo assim, elas serão classificadas como estações do tipo de transmissão estendido por deterem pelo menos um fluxo de transmissão estendido. Na segunda janela ATIM, as estações B e C ainda permanecem trocando pacotes de dados. Por este motivo, elas estarão impossibilitadas de decodificar os pacotes de controle dos vizinhos. Elas classificarão os seus vizinhos como tipo Unknown até o momento em que forem enviados pacotes de controle para o conhecimento e atualização das suas estruturas NIL. A estação A participa mais uma vez da fase de negociação por ter sido classificada como uma estação do tipo Normal no primeiro beacon. Mais três negociações são realizadas com sucesso, agora entre as estações A, D e E. Sob a perspectiva dos vizinhos, as estações B e C são classificadas como Normal, Ongoing e Limited nos beacons de números 1, 2 e 3, respectivamente. De forma particular, as estações B e C se auto classificam como Normal nos beacons de números 1 e 3, e como Ongoing no beacon 2.

Ainda é possível que as estações necessitem transmitir em difusão pacotes ATIMBRD (broadcast) a todos os vizinhos. A abordagem híbrida aqui proposta também deve prover suporte a este tipo de transmissão.

\section{Modelo Analítico}

Os protocolos multicanais apresentados neste trabalho baseiam-se no Padrão 802.11 DCF (do inglês Distributed Coordination Function). Sendo assim, foi adotado o modelo de avaliação de desempenho proposto em [Tinnirello et al. 2010] que apresenta refinamentos importantes do trabalho proposto em [Bianchi 2000]. O modelo utiliza uma cadeia de Markov bidimensional de tempo discreto com dois processos estocásticos $b(t)$ e $s(t)$, representando o contador de resguardo de uma determinada estação e o estágio de resguardo referente ao número de transmissões mal sucedidas de um pacote no tempo $t$ (pacote HOL, do inglês Head-of-line), respectivamente. Considerando que os modelos analíticos dos protocolos avaliados são fundamentados sob a métrica da vazão agregada de saturação, todas as estações da rede sempre terão pacotes de dados em seus buffers a serem transmitidos.

\subsection{Modelo Analítico do Novo Protocolo H-M2MMAC Proposto}

São consideradas $C$ estações disponíveis na rede. Quando o sistema está saturado, $C^{a}$ estações estarão no canal de controle durante a janela ATIM tentando estabelecer negociações, enquanto as $C^{d}$ estações restantes estarão distribuídas entre os canais de dados no modo de transmissão estendido. Assim como o M2MMAC, o H-M2MMAC utiliza apenas um período de contenção, a saber, a janela de negociação do canal de controle. Porém, o período de contenção será disputado apenas pelas estações que não estabeleceram fluxos de transmissão do tipo estendido na janela ATIM antecedente, ou seja, as estações do grupo $C^{a}$. Sendo assim, o número de fluxos de transmissão máximos jamais poderá ser superior a $C^{a}\left(C^{a}-1\right)$. Como o número de estações comunicantes no período posterior à negociação $(P)$ não poderá ultrapassar o quantidade total de $M$ canais disponíveis, este número deve ser definido como $P=\min \left\{M, C^{a}\right\}$. Consequentemente, a quantidade máxima de fluxos de transmissão da rede será representada por $P(P-1)$. Como a quantidade de fluxos de transmissão de cada estação é limitada pela quantidade 
de antenas disponíveis, então a quantidade máxima de fluxos da rede também poderá ser representada por $P(B-1)$.

Como cada canal só pode ser ocupado por uma única estação, então $C^{d}$ sempre será igual a 1. Sendo assim, a quantidade de canais que estarão sendo utilizados no período posterior à negociação ficará limitado ao número $P$ de nós participantes neste período. Consequentemente, o número de estações que estarão no canal de controle durante a janela ATIM $\left(C^{a}\right)$ deverá ser definido como $C^{a}=C-(P-1)$.

O número máximo de transmissões de pacotes de dados que podem ser acomodadas em uma janela de comunicação por fluxo de transmissão $\left(n_{\max }\right)$ ficará fadado somente ao canal padrão de controle. Isso porque nos demais canais de dados que estarão sendo utilizados por nós que utilizam o método estendido, a comunicação prolongar-se-á até o fim da próxima janela ATIM. Sendo assim, os pacotes de dados poderão ser acomodados em um espaço de tempo equivalente a um intervalo entre beacons. Dito isso, o número máximo de transmissões de pacotes de dados por fluxo de transmissão que podem ser acomodadas em um período de tempo equivalente a um intervalo entre beacons $\left(n_{\max _{B E A C O N}}\right)$ é dado por $n_{\max _{B E A C O N}}=\left\lfloor\frac{l_{\text {beacon }}}{l_{\text {slot }}}\right\rfloor$, em que $\lfloor x\rfloor$ simboliza o maior inteiro menor ou igual a $x$ e $l_{\text {beacon }}$ é a duração de um intervalo entre beacons. Considerando a equação da vazão agregada de saturação do M2MMAC, proposta em [Ghobad 2017], a equação pode ser ajustada para o H-M2MMAC, resultando

$$
S^{H M 2 M M A C}=\frac{\min \left\{P(P-1), P(B-1), n_{\text {sched }}\right\}\left(\frac{n_{\max }}{P}+n_{\left.\max _{B E A C O N} \frac{P-1}{P}\right) D A T A}\right.}{l_{\text {beacon }}},
$$

onde DAT A representa o tamanho do pacote de dados em bits, o termo $n_{\text {sched }}$ é o número médio de fluxos de transmissão negociáveis em uma única Janela ATIM, o termo $\left(\frac{n_{\max }}{P}\right)$ é o número máximo de transmissões de pacotes de dados no canal padrão de controle, e

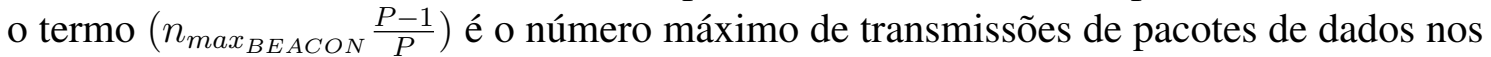
demais canais de dados que estão sendo utilizados pelas estações no modo estendido de transmissão.

Para que todos os canais de dados possam ser utilizados no modo estendido de comunicação, é necessário que os critérios para a rede com alta carga dedados sejam satisfeitos para todos os canais de dados. Adicionalmente, o número de estações no canal padrão de controle durante a janela ATIM $\left(C^{a}\right)$ deve ser maior que $P$. Sendo assim, conclui-se que se $C \geq 2 P-1$, as estações utilizam o modo estendido de transmissão, e o H-M2MMAC supera o M2MMAC neste quesito de desempenho.

\section{Avaliação de Desempenho}

Os resultados obtidos por meio do modelo matemático são examinados em função de quatro parâmetros: (1) o número de estações na rede $(C)$; $(2)$ o número de canais de frequência não sobrepostos disponíveis $(M)$; (3) a duração do intervalo de negociação (ATIM Window); (4) e o número de antenas de recepção $(B)$. É considerado um intervalo entre beacons de $100 \mathrm{~ms}\left(l_{\text {beacon }}=100 \mathrm{~ms}\right)$ e pacotes de dados com 512 Bytes $(D A T A=$ 512 Bytes).

As expressões utilizadas para a vazão agregada de saturação de cada um dos protocolos comparados são apresentadas em [So and Vaidya 2004, Dang et al. 2015, Zhang et al. 2007, Ghobad 2017]. Conforme descrito em [Ghobad 2017], a sobrecarga 
dos protocolos pode exercer grande impacto em seus desempenhos em termos de vazão de saturação. Nesse sentido, para investigar mais adequadamente o desempenho de cada protocolo, os resultados das vazões de saturação serão obtidos considerando-se apenas a carga útil do pacote de dados (payload). Serão desconsiderados os bits utilizados para cabeçalhos da camada MAC e da camada PHY. Sendo assim, pode-se afirmar que esta avaliação considera apenas o goodput da transmissão.

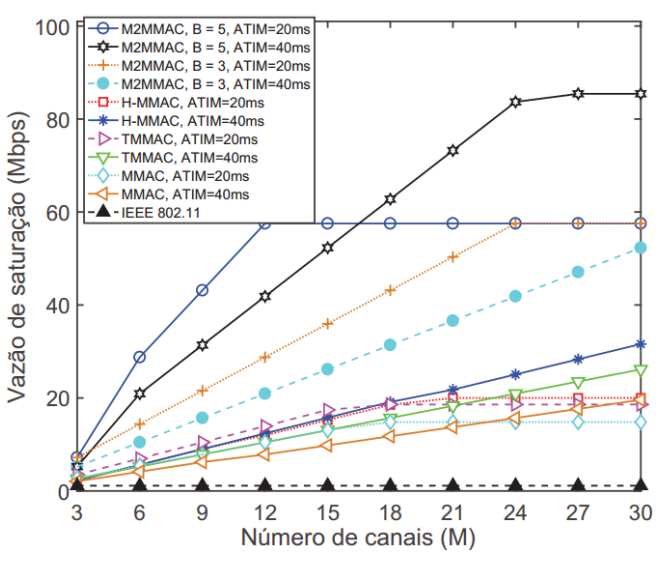

(a) Protocolos correlatos ao H-M2MMAC. Fonte: [Ghobad 2017]

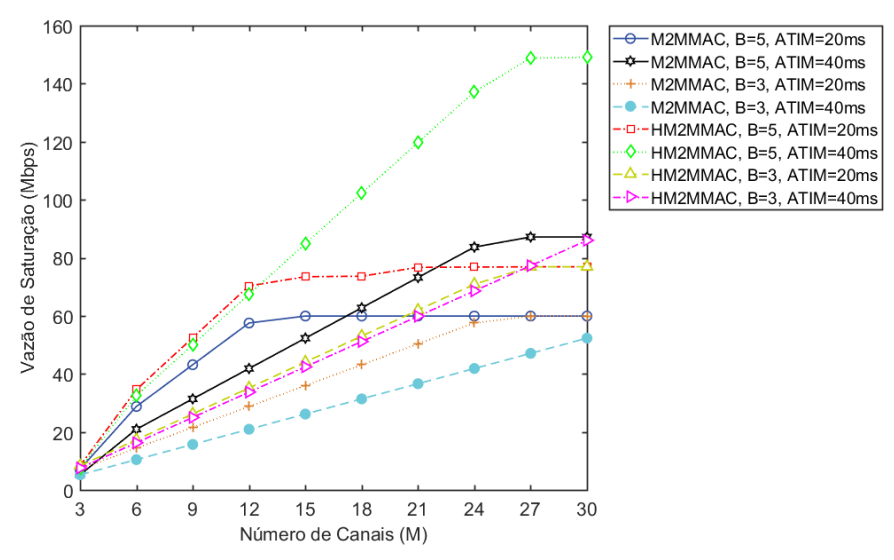

(b) Protocolos M2MMAC e H-M2MMAC

Figura 3. Vazão agregada de saturação versus número de canais disponíveis (M).

A Figura 3(a), apresentada em [Ghobad 2017], indica as vazões agregadas de saturação dos protocolos IEEE 802.11 DCF, MMAC, TMMAC, H-MMAC e M2MMAC em função do número de canais não sobrepostos disponíveis $(M)$ e com 60 estações disputando o canal de controle $(C=60)$. O M2MMAC supera os outros protocolos em função do número de canais disponíveis. Como o 802.11 DCF utiliza somente um canal, sua vazão permanece constante e inalterável com o aumento do número de canais, diferentemente dos demais protocolos multicanais. Para o protocolo M2MMAC, é importante citar que a vazão satura quando se atinge um determinado número de canais. Isso ocorre porque mesmo com um número crescente de canais, torna-se inviável o estabelecimento de um número maior de negociações caso a janela ATIM não tenha uma duração suficiente, fazendo com que os recursos da janela de comunicação fiquem subutilizados.

A Figura 3(b) indica as vazões agregadas de saturação em função do número de canais não sobrepostos disponíveis $(M)$, porém considerando agora os protocolos M2MMAC e H-M2MMAC. A quantidade de estações disputando o canal de controle permanece a mesma do exemplo anterior $(C=60)$. Quando as estações são equipadas com cinco antenas de recepção $(B=5)$, a rede possui 30 canais disponíveis $(M=30)$, e a duração da janela ATIM é de 40ms ( $A T I M=40 \mathrm{~ms}$ ), o protocolo H-M2MMAC apresenta um acréscimo de aproximadamente $74 \%$ da vazão em relação ao M2MMAC, sendo este o melhor caso observado.

A Figura 4 apresenta a influência da duração da Janela ATIM na vazão de saturação da rede com 60 estações disputando o canal de controle para os protocolos M2MMAC e H-M2MMAC. O desempenho da rede é posto em prova para diferentes combinações de números de antenas de recepção $(B)$ e canais disponíveis $(M)$ em função da duração da 
janela ATIM. Para o protocolo M2MMAC, especificamente para os casos onde $M=12$ e $B \neq 2$, as curvas crescem até alcançarem um valor máximo. Neste ponto, a janela ATIM já possui um intervalo suficiente para acomodar todas as negociações de fluxos de transmissão que os recursos disponíveis podem tolerar. A partir daí, as curvas começam a decair, demostrando que mesmo que a janela ATIM tenha um intervalo suficientemente longo para troca de pacotes de controle, a rede perde desempenho, pois o intervalo da janela de comunicação diminui. Para os demais casos, observa-se que as curvas sempre tendem a decair.

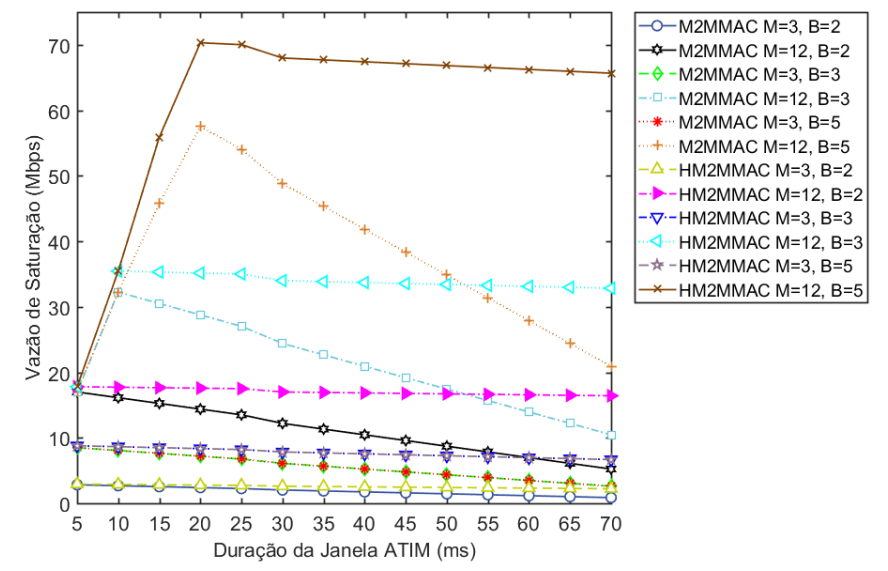

Figura 4. Influência da duração da Janela ATIM na vazão agregada de saturação para diferentes números de antenas de recepção e canais de transmissão disponíveis com $\mathrm{C}=60$ estações.

Para o protocolo H-M2MMAC, a rede consegue obter um desempenho estabilizado na maioria dos casos, mesmo que o intervalo da janela ATIM cresça. Além disso, o desempenho continua superior ao do protocolo M2MMAC. Isso ocorre devido à característica de troca de pacotes no intervalo de negociação dos canais de dados enquanto os pacotes de controle são trocados na janela ATIM do canal de controle. O H-M2MMAC apresenta, em seu melhor caso, desempenho três vezes maior que o protocolo M2MMAC para as curvas onde $M=12$ e $B=5$, e para o caso onde o intervalo da janela ATIM é de $70 m s(A T I M=70 \mathrm{~ms})$.

A Figura 5(a), apresentada em [Ghobad 2017], indica as vazões agregadas de saturação dos protocolos IEEE 802.11 DCF, MMAC, TMMAC, H-MMAC e M2MMAC enquanto aumenta-se o número de nós participantes $(C)$ para uma quantidade fixa de canais $(M=24)$. O M2MMAC destaca-se mais uma vez em todos os casos. Quando as estações são equipadas com cinco antenas de recepção $(B=5)$, a duração da janela ATIM é de $20 \mathrm{~ms}(A T I M=20 \mathrm{~ms})$, e a rede possui sessenta estações participantes $(C=60)$, o protocolo M2MMAC provê o triplo da vazão quando comparado ao protocolo H-MMAC sob a mesma configuração. Observa-se ainda que, para as curvas do M2MMAC onde as estações são equipadas com cinco antenas de recepção $(B=5)$, a curva com um intervalo menor da janela ATIM ( $A T I M=20 \mathrm{~ms}$ ) apresenta uma vazão de saturação superior à curva com um intervalo de 40ms ( $A T I M=40 \mathrm{~ms}$ ) para um pequeno número de estações ( $C<17$, aproximadamente). Porém, com o aumento do número de estações, a vazão da curva com $20 \mathrm{~ms}$ começa a decrescer. Isso acontece devido ao fato de que são negociados 
um número menor de fluxos de transmissão na janela ATIM. Sendo assim, a configuração com 40ms mostra-se mais promissora para uma faixa maior de estações participantes na rede observada.

A Figura 5(b) indica as vazões agregadas de saturação em função do número de estações participantes da rede, porém considerando agora os protocolos M2MMAC e HM2MMAC. As curvas características do H-M2MMAC sempre começam em desvantagem quando comparadas às curvas do M2MMAC sob as mesmas configurações. Isso ocorre porque o número de estações na rede não é o suficiente para caracterizar uma rede com alta carga de dados. Na verdade, isso indica que, em casos onde a rede possui uma baixa carga de dados, é desvantajoso utilizar o modelo de transmissão estendida. À medida que o número de estações cresce, a carga da rede vai aumentando, e consequentemente, a vazão do protocolo H-M2MMAC se sobressai. Com uma quantidade pequena de estações disputando o canal de controle durante a janela ATIM, a rede consegue alcançar o número máximo de negociações em um intervalo de tempo reduzido. Sendo assim, o tamanho da Janela ATIM é um importante parâmetro a ser considerado para aumentar a eficiência do protocolo na utilização dos recursos disponíveis.

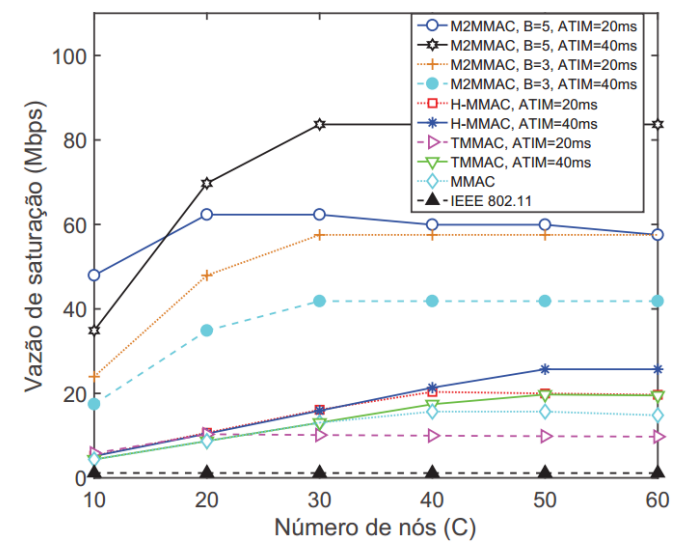

(a) Protocolos correlatos ao H-M2MMAC. Fonte: [Ghobad 2017]

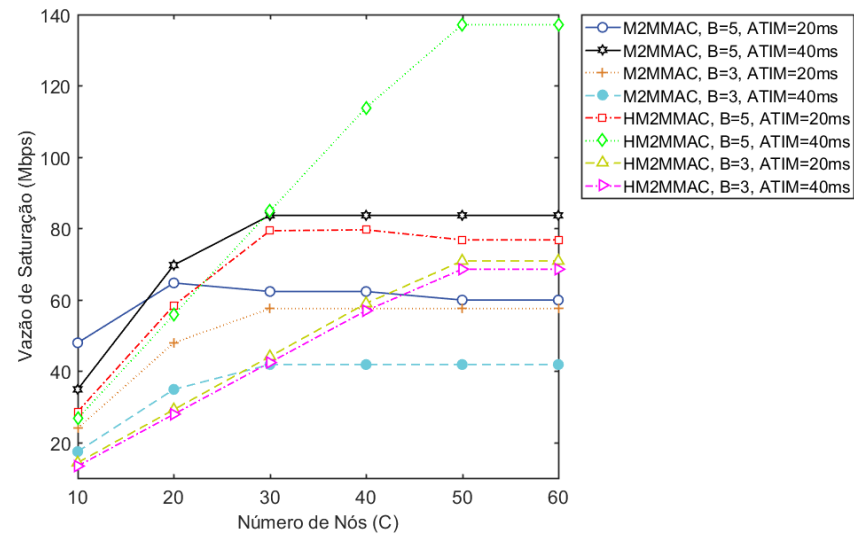

(b) Protocolos M2MMAC e H-M2MMAC

Figura 5. Vazão agregada de saturação versus número de estações participantes (C) da rede com uma quantidade fixa de canais disponíveis $(M=24)$.

\section{Conclusões e Trabalhos Futuros}

Neste artigo, foi proposto um novo protocolo híbrido e adaptativo MAC multicanal para comunicação muitos-para-muitos do tipo Split Phase denominado H-M2MMAC. Um modelo analítico foi proposto com o objetivo de se avaliar o desempenho do protocolo em termos de vazão agregada de saturação. O H-M2MMAC mostrou-se superior aos demais protocolos multicanais relacionados. Foi constatada a necessidade de se adequar a duração da janela ATIM face ao número de canais de recepção e às antenas disponíveis, além do número de estações participantes na rede. Com o crescimento do número de antenas, foram necessários intervalos de negociação maiores para que todos os recursos da rede fossem utilizados de maneira eficaz. O protocolo $\mathrm{H}-\mathrm{M} 2 \mathrm{MMAC}$ mostrou-se vantajoso em quesitos de comunicação estendida para a rede com alta carga de dados. Porém, caso o número de estações seja pequeno, o protocolo perde eficiência, tendo em vista que o 
modelo foi aplicado para situações de saturação da rede, e que sob estas circunstâncias, as estações sempre transmitiriam no modo estendido.

Como trabalhos futuros, é importante que o modelo matemático seja validado através de simuladores de rede. Além disso, é interessante considerar a vazão agregada em casos onde a carga do tráfego da rede está baixa, validando de maneira mais realista a abordagem híbrida aqui proposta. Também pode ser verificado o desempenho do protocolo sob a perspectiva de atrasos fim a fim. Uma análise comparativa e simplificada em relação à sobrecarga do H-M2MMAC durante a fase de comunicação com a sobrecarga dos outros protocolos aqui apresentados é outro trabalho futuro a ser considerado. E por fim, impactos de limitações da camada física (PHY) no protocolo H-M2MMAC devem ser analisados.

\section{Referências}

Bianchi, G. (2000). Performance Analysis of the IEEE 802.11 Distributed Coordination Function. IEEE Journal on selected areas in communications, 18(3):535-547.

Dang, D. N. M., Hong, C. S., and Lee, S. (2015). A Hybrid Multi-Channel MAC Protocol for Wireless Ad Hoc Networks. Wireless Networks, 21(2):387-404.

de Moraes, R. M. (2005). Performance Analysis of Wireless Networks. PhD thesis, University of California, Santa Cruz, California.

de Moraes, R. M., Sadjadpour, H. R., and Garcia-Luna-Aceves, J. (2009). Many-toMany Communication for Mobile Ad Hoc Networks. IEEE Transactions on Wireless Communications, 8(5):2388-2399.

Ghobad, P. C. (2017). M2MMAC: Um Novo Protocolo MAC Multicanal para Comunicação Muitos-para-Muitos em Redes 802.11. Master's thesis, Universidade de Brasília, Brasília.

IEEE Computer Society LAN MAN Standards Committee (1997). Wireless LAN Medium Access Control (MAC) and Physical Layer (PHY) Specifications. IEEE Standard 802.11-1997.

Mo, J., So, H.-S. W., and Walrand, J. (2008). Comparison of Multichannel MAC Protocols. IEEE Transactions on mobile computing, 7(1):50-65.

Rubinstein, M. G., Moraes, I. M., Campista, M. E. M., Costa, L. H. M., and Duarte, O. C. M. (2006). A Survey on Wireless Ad Hoc Networks. In Mobile and Wireless Communication Networks, pages 1-33. Springer.

So, J. and Vaidya, N. H. (2004). Multi-Channel MAC for Ad Hoc Networks: Handling Multi-Channel Hidden Terminals using a single transceiver. In Proceedings of the 5th ACM International Symposium on Mobile Ad Hoc Networking and Computing, pages 222-233. ACM.

Tinnirello, I., Bianchi, G., and Xiao, Y. (2010). Refinements on IEEE 802.11 Distributed Coordination Function Modeling Approaches. IEEE Transactions on Vehicular Technology, 59(3):1055-1067.

Zhang, J., Zhou, G., Huang, C., Son, S. H., and Stankovic, J. A. (2007). TMMAC: An Energy Efficient Multi-Channel MAC Protocol for Ad Hoc Networks. In Communications, 2007. ICC'07. IEEE International Conference on, pages 3554-3561. 